\title{
Attention and cognitive control as emergent properties of information representation in working memory
}

\author{
SUSAN M. COURTNEY \\ Johns Hopkins University, Baltimore, Maryland
}

\begin{abstract}
A hallmark of primate, and particularly human, behavior is cognitive control, the ability to integrate information from a multitude of sources and use that information to flexibly guide behavior in order to achieve an infinite number of goals. The neural mechanisms of cognitive control have yet to be fully elucidated, although the prefrontal cortex is known to play a critical role. Here, I review evidence suggesting that a unifying principle regarding the role of various portions of the prefrontal cortex in a wide range of cognitive tasks is the active maintenance in working memory of different types of currently relevant information - from specific stimulus features, to instructional cues, to motivational goals and contexts. I argue that the key to demonstrating the existence of this domain-dependent organization lies in a better understanding of the nature of the representation of this information and the ways in which this information itself controls cognition and behavior.
\end{abstract}

The function of every part of the brain is determined by the type of information it receives, how that information is transformed by the internal circuitry of that brain area, and where its output goes. The prefrontal cortex (PFC) has extensive reciprocal connections with sensory systems, the medial temporal lobe, and the motor system, as well as with subcortical areas (Barbas \& Pandya, 1989; Cavada \& Goldman-Rakic, 1989; Petrides \& Pandya, 2002). Thus, it receives multimodal information about the current environment and has access to previously stored memories. The PFC's extensive outputs allow for direct control of motor behavior, but they may also influence behavior indirectly by altering perceptual and cognitive representations and influencing the storage and retrieval of long-term memories.

A notable feature of the PFC is its ability to demonstrate sustained activation representing task-relevant information in the absence of sensory input, or even in the face of distracting, irrelevant sensory input (e.g., Constantinidis, Franowicz, \& Goldman-Rakic, 2001b; Fuster \& Alexander, 1971; Miller, Erickson, \& Desimone, 1996). Although the neural mechanism of this sustained activity is not completely known, one prominent theory is that it is achieved through reentrant connections both within the PFC and with other brain areas (e.g., Constantinidis, Franowicz,

This work was supported by National Institutes of Health Grant R01 MH61625. The author thanks the entire staff of the F. M. Kirby Research Center for Functional Brain Imaging, where the data were collected, and Leslie Ungerleider, Steve Yantis, Matthew Albaugh, Katherine Roe, Jennifer Roth, and Seema Sayala for helpful comments on an earlier draft of this article. Correspondence concerning this article should be addressed to S. M. Courtney, Department of Psychological and Brain Sciences, Johns Hopkins University, 227 Ames Hall, 3400 N. Charles Street, Baltimore, MD 21218 (e-mail: courtney@jhu.edu).
\& Goldman-Rakic, 2001a; Fuster, 2001; Fuster, Bauer, \& Jervey, 1985; Goldman-Rakic, 1987, 1995b). This sustained activity is thought to underlie the PFC's ability to bridge temporal gaps between stimuli and behavior (e.g., Fuster, Bodner, \& Kroger, 2000) through a process referred to as working memory (WM). WM is the sustained active representation of a limited amount of currently relevant information so that it is available for use.

\section{Defining Type of Information and Domain-Dependent Organization}

The term working memory has traditionally been associated with the maintenance of specific stimulus features, such as phonological, visual, or spatial information (Baddeley \& Hitch, 1974; Baddeley \& Logie, 1999). WM is often studied using tasks that require the maintenance of these types of information, such as delayed response and delayed recognition tasks (e.g., Funahashi, Bruce, \& Goldman-Rakic, 1989; Fuster \& Alexander, 1971; Postle \& D’Esposito, 1999; Rao, Rainer, \& Miller, 1997; Sala, Rämä, \& Courtney, 2003). The recent literature, reviewed below, seems to support the idea that simple maintenance of stimulus features is organized in a domain-dependent fashion within posterior PFC regions (e.g., Brodmann area [BA] 45/47 for object and verbal information versus BA 8 for spatial information in humans), in general agreement with the original model proposed by Patricia Goldman-Rakic (Wilson, Ó Scalaidhe, \& Goldman-Rakic, 1993; see the review in Levy \& Goldman-Rakic, 2000). More anterior regions (such as BAs 46/9 and 10 in humans) have been considered by many to be domain independent because they do not consistently differentiate between stimulus features, such as object identity and location. However, the concept of WM and the mecha- 
nisms that enable active maintenance of stimulus features can be extended to other, more abstract types of information. For example, sustained activation of an individual's current environmental context and task goals is also necessary for flexible behavior and higher cognitive processing. The PFC likely plays a role in maintenance of these types of information as well. The maintenance of task- and goal-related information is necessary in order to define which new perceptual inputs are irrelevant (i.e., distracting) and which should be encoded and entered into the WM buffer (see also, e.g., Braver \& Cohen, 2000).

In this article, therefore, I define type of information more broadly than is usually considered in debates regarding the existence of a domain-specific organization of WM. Type of information here includes context, instructions, motivation, strategies, plans, and any other type of information that might be gathered through sensory input or experience, in addition to stimulus features such as spatial locations, objects, and verbal information. I will summarize evidence supporting the view (GoldmanRakic, 1995a) that the underlying function of all the regions of the PFC is the creation and maintenance of integrated representations of all relevant information. The representation of much of this information is more complex and abstract than simple stimulus features, however. Differences in processing and differential involvement in various types of cognitive tasks between regions of the PFC are necessary consequences of the different types of information being maintained. The type of information being maintained, rather than the type of processing, however, is the fundamental organizing principle (see Figure 1).

Many theories include information type as at least one aspect of the functional organization of the PFC. For example, Miller and Cohen have suggested that apparent differences in processing between different regions of the PFC may arise because some types of information (e.g., social and appetitive information processed primarily in the orbital PFC) have more prepotent stimulus-response associations than others do (e.g., particular stimulus features, such as color or location, processed more predominantly in the lateral PFC) and would, therefore, require different amounts of excitation or inhibition in order to produce the appropriate behavior for the current context and goals (Miller \& Cohen, 2001; O'Reilly, Noelle, Braver, $\&$ Cohen, 2002). Such processing differences may be more than apparent, however. For example, within the visual system, the dorsal stream is concerned primarily with spatial information, whereas the ventral stream is concerned primarily with nonspatial information. The types of processes performed by the two visual systems depend on the types of representations of that information that are useful to the organism. The dorsal stream transforms spatial information from retina-centered to head-, body-, and environment-centered coordinates. This information is necessary for proper allocation of attention and direction of motor movements. The ventral

\section{Emergent Properties of Information Representation}

Functional Topography by Information Type

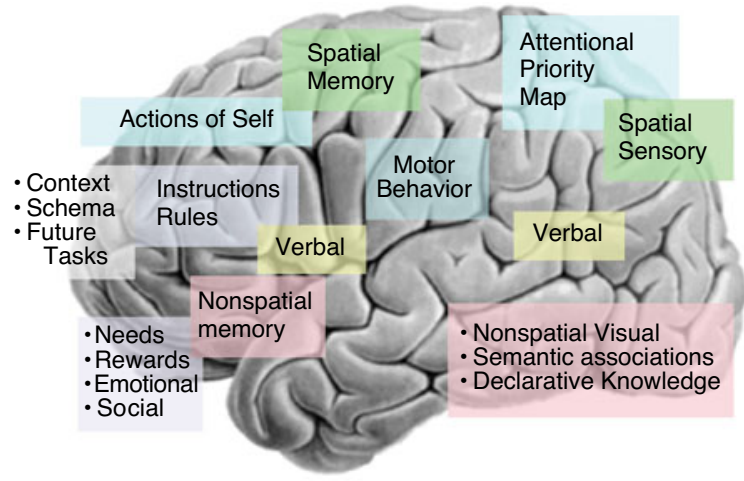

Converging and Diverging Information

Creates Dynamic Integrated Representations in PFC ...

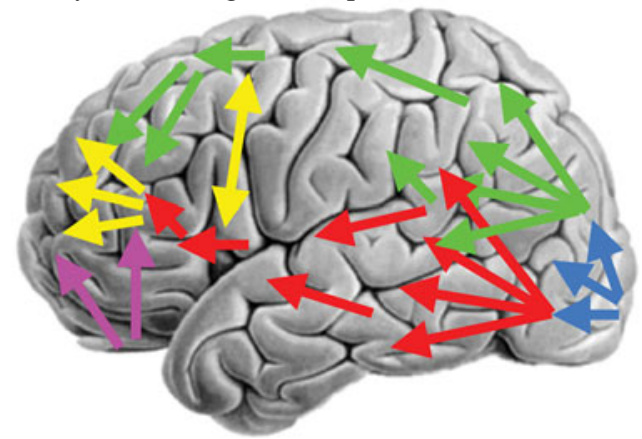

. and Controls Access in Awareness and Working Memory

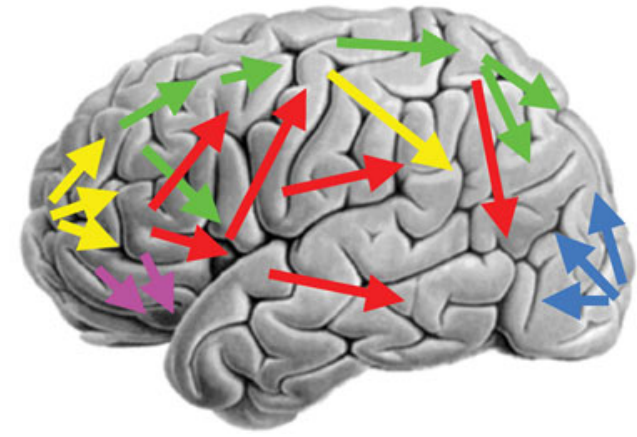

Figure 1. Summary of the functional organization of the cerebral cortex by information type. Shown are examples of only some of the types of information represented and their approximate neuroanatomical relationships. Arrows illustrate how convergent and divergent feedforward pathways (both hierarchical and parallel) could serve to integrate multiple sources of information both within and outside the prefrontal cortex (PFC). Likewise, convergent and divergent feedback projections allow the integrated representation within the PFC to bias competitive interactions throughout the brain, influencing cognition, perception, and behavior.

stream, however, progressively transforms retinotopic patterns of neural activity into semantic representations of objects. Different kinds of information have different properties and different types of influence on behavior, necessitating different kinds of processing to create the 
most appropriate and useful representation of that information. Similarly, the mid-dorsolateral and anterior prefrontal cortex, which have been suggested as being necessary for such processes as manipulation and attentional selection, may be more involved in tasks that require these cognitive operations, because these regions maintain more abstract information, such as increasingly more complex relationships and contingencies, defining the environmental context and strategies for attaining current goals. Such a representational view defines processing as a means for creating more useful and more complete representations of information (Wood \& Grafman, 2003).

In the framework presented here, when a particular piece of information is relevant and active, it is considered to be in WM. When something was previously unavailable or irrelevant and then becomes both available (e.g., part of the current sensory input) and relevant (according to the goals represented in WM), it will become actively maintained and, thus, enter WM. When something that was being actively maintained becomes irrelevant, the reentrant circuits that maintain that information will no longer refresh that information, and it will leave WM. So in this sense, the proposed model is similar to a traditional buffer model. The difference is that in the currently proposed model, the information in WM consists of both sensory information and more abstract information in a distributed hierarchical network, and the active representation of the information is dynamic, modifiable by interactions among multiple cortical regions. Information does not explicitly enter or leave a localized WM module.

The research reviewed here and the interpretation presented stems from two fundamental principles of Patricia Goldman-Rakic's work: that WM is the basis of all the higher cognitive functions and that the PFC is primarily organized according to the type of information to be maintained. Understanding the nature of the representation of a broad variety of types of information within the PFC may be fundamentally important to understanding the overall functional organization of the PFC and the differential involvement of the various regions of the PFC in different types of tasks. However, the nature of the representation of this information may not be straightforward. As I will discuss below, even though a large body of research supports the distinction made by Goldman-Rakic between WM for locations and WM for objects (Levy \& Goldman-Rakic, 2000; Wilson et al., 1993), this distinction does not fully capture the nature of the functional topography for stimulus features across the dorsal and the ventral posterior lateral PFC. Instead, as we have previously proposed (Sala et al., 2003), the nature of the dorsal/ventral dissociation might be better considered to be based on a dissociation between spatial and nonspatial stimulus features, with the representation of objects containing both spatial and nonspatial visual features. In addition, the relationships among such stimulus features are another type of information that may be represented in the PFC when such information is useful and relevant. These relationships appear to be represented through interactions between the feature-specific regions, rather than in a separate region of the PFC. However, other kinds of information, such as whether such relationships are relevant, the conditions for determining their relevance, and mechanisms for creating new relationships, appear to be represented in a hierarchical fashion in more anterior regions.

Relationship of WM to attention and cognitive control. I suggest that attention and cognitive control are not directed actions or specific processes contained within any particular set of brain regions. Rather, what we experience and observe that we call attention and cognitive control are emergent properties dependent on the distributed representation of all types of information, both that available from present perceptual input and the information currently sustained in WM, including contextual and motivational information. The use of the term emergent properties means that attention and cognitive control arise as a consequence of WM, but are not separate entities that are specifically implemented by the brain. For example, attentional selection is the consequence of biases in perceptual processing that arise directly from the representation in WM of the relative importance of one location, object, or feature over another. In this case, a domain-general attentional selection control process would not be localizable to any particular brain region.

This representation of all currently relevant information is constantly changing as new information enters the system. Information representations in multiple brain areas influence the representation of information in many other brain areas. This influence may take the form of either direct input to a specific brain area or the modulation of functional connectivity between brain areas. The particular influence that this active information state has on cognition and behavior and the representation of the information itself depend on the unique structure of the individual system, which has been shaped through development and experience. In other words, to the extent that each person's brain, cumulative knowledge, and current perceptual information are unique, so too will each person's cognitive state and behavior be unique. Thus, individual "decisions" are not "controlled" by a homunculus but arise as a consequence of that person's unique current and past experience and biological structure. To the extent that we are unaware of all of the information contributing to a behavior or a cognitive state, and because there is noise and uncertainty in the system, we experience a sense of what we call control.

\section{Evidence for a Domain-Dependent PFC Organization}

In considering whether information type plays a role in the organization of the PFC, Goldman-Rakic and her colleagues (Wilson et al., 1993) proposed that the PFC shows evidence of a dissociation similar to that observed 
in the visual system, in which ventral visually responsive cortical regions represent information essential for object identification, whereas more dorsal regions represent the egocentric and allocentric spatial locations of those objects and are essential for making reaching and grasping movements and for directing attention to objects and/or locations (Goodale \& Milner, 1992; Ungerleider \& Haxby, 1994; Ungerleider \& Mishkin, 1982).

Recent evidence for dual object and location selectivity in single prefrontal neurons (Rainer, Asaad, \& Miller, 1998a; Rao et al., 1997), dynamic changes in selectivity according to task demands (Freedman, Riesenhuber, Poggio, \& Miller, 2003; Rainer, Asaad, \& Miller, 1998b; Wallis, Anderson, \& Miller, 2001), and differential involvement of different regions of the PFC according to the processing and contextual complexity of the task independently of stimulus features (e.g., D'Esposito, Postle, Ballard, \& Lease, 1999; D’Esposito, Postle, \& Rypma, 2000; Owen, Evans, \& Petrides, 1996; Petrides, 1995a) has demonstrated that stimulus features (e.g., object identity and location) are not the only organizing principles of the PFC. However, there is a large body of evidence supporting a dorsal/ventral stimulus-feature-dependent functional topography, at least within the posterior portions of the PFC (i.e., BAs 8 and 45/12).

The key to accounting for all of these seemingly contradictory experimental results and resolving this controversy, I will argue, is in understanding both the nature of the domain-dependent dissociations and the ways in which different regions of the PFC interact. Interactions within the PFC could create new integrated representations of the information when, but only when, such an integrated representation is useful to the current task and goals of the individual. Cells in the PFC appear to be able to code both sensory aspects of stimuli to be remembered (Constantinidis et al., 2001a) and more abstract information, such as task rules (Wallis et al., 2001). In the view presented here, the task rules (perhaps represented in BA 46) and the goals of the individual are also influenced by the system of biases created by an integrated representation of all available information, including current and future needs, instructional cues, and reward expectations actively maintained in progressively more anterior regions of the PFC.

I will begin, however, by reviewing some of the evidence supporting the original model of object WM achieved via the ventral PFC and spatial location WM achieved via the dorsal PFC. (For a more extensive review of monkey physiology, anatomy, and lesion studies on this topic, see Levy \& Goldman-Rakic, 2000.)

Evidence for what versus where in the PFC. A large part of the confusion in both current and past debates over the nature of the functional organization of the PFC stems from uncertainty regarding the anatomical definitions of functional subregions within the PFC. The use of the term dorsolateral prefrontal cortex (DLPFC) has included BAs (or Walker's areas) 8, 46, and 9. (Some definitions have also included areas 45, 47, and 44, al- though we will refer to these as the ventrolateral PFC.) Without cytoarchitectonic analysis, one cannot be certain in which of these regions the particular patch of cortex being investigated belongs, because of the individual variability across individuals (Rajkowska \& GoldmanRakic, 1995). This uncertainty, combined with the imprecision of both natural and experimentally induced lesions and the complex interactions among PFC regions, has led to a seemingly contradictory collection of experimental results.

Early research by Fuster and his colleagues indicated that the DLPFC reflected both spatial and nonspatial information. For example, although some studies have shown that lesions in the DLPFC selectively disrupted spatial WM tasks, and not nonspatial tasks (e.g., Mishkin \& Manning, 1978; see Levy \& Goldman-Rakic, 2000, for a thorough review), a study by Bauer and Fuster (1976) indicated that cooling of the DLPFC affected performance on both nonspatial delayed match to sample and spatial delayed response tasks. Studies by Petrides (1995b) and his colleagues also demonstrated deficits in both spatial and nonspatial WM tasks following DLPFC lesions. In addition, single-cell recordings have demonstrated delay period selectivity to both the color of the sample stimulus and the direction of the impending response (Quintana, Yajeya, \& Fuster, 1988), and this selectivity depended on the behavioral relevance of the information (Yajeya, Quintana, \& Fuster, 1988). However, a study by Wilson et al. (1993) and subsequent studies by GoldmanRakic and her colleagues (e.g., Ó Scalaidhe, Wilson, \& Goldman-Rakic, 1997, 1999) have indicated a spatial/ nonspatial information domain dissociation between more dorsal PFC regions (Walker's areas $8 \mathrm{~A}$ and 46 ) and more ventral PFC regions (Walker's areas 45 and 12).

This seemingly contradictory collection of results can be understood if one considers the interactions among PFC regions, which will be discussed below, and a more complex view of the functional anatomy of the PFC, rather than broad classifications, such as dorsal versus ventral. The functional topography of the posterior PFC (including areas $8 \mathrm{~A}$ and $45 / 12$ in the monkey), unlike more anterior regions (e.g., areas 46, 9, and 10), appears to be based, at least in part, on primary features of the stimulus to be maintained in delayed recognition tasks. This organization most likely arises primarily from the differential pattern of inputs across the PFC from functionally distinct pathways, such as those within the visual (Barbas \& Pandya, 1989) and the auditory (Romanski et al., 1999) systems. In the monkey, although there are some overlapping projections, the preponderance of visual system input to the DLPFC (BAs 46/9 and 8) is from the parietal cortex, whereas the preponderance of visual input to the ventrolateral PFC (BA 12) is from the temporal cortex. Lesions of the posterior part of the principal sulcus in monkeys impair spatial, but not object, WM (Mishkin \& Manning, 1978). Likewise, disruptions in the function of the cortex within the posterior portion of the superior frontal sulcus in humans, either from 
stroke (Carlesimo, Perri, Turriziani, Tomaiuolo, \& Caltagirone, 2001) or from transcranial magnetic stimulation (Mottaghy, Gangitano, Sparing, Krause, \& Pascual-Leone, 2002) selectively disrupt spatial WM.

Conversely, some results in humans suggest selective impairment on nonspatial WM tasks after disruption of the ventral PFC (Bechara, Damasio, Tranel, \& Anderson, 1998; Mottaghy et al., 2002). The results of lesions to the inferior convexity in monkeys have been mixed, depending on the precise location of the lesion, the parameters of the task, and the length of the retraining/recovery period (for a review, see Levy \& Goldman-Rakic, 2000). These results suggest that the dissociation between the dorsal and the ventral PFC for location and object WM may not be symmetrical. In a study by Rushworth, Nixon, Eacott, and Passingham (1997), small ventral PFC lesions disrupted neither spatial nor object WM tasks, whereas large lesions disrupted both types of tasks. If, as will be suggested below, the representation of objects is more distributed across both dorsal and ventral visualprocessing streams (and corresponding PFC regions) than is the representation of locations, object tasks might be more robust to the effects of small lesions in the ventral PFC than are spatial location tasks to the effects of lesions in the dorsal PFC. Large ventral PFC lesions might have involved additional portions of the PFC necessary for aspects of the task other than representation of specific stimulus features. Alternatively, it may be that we do not yet know precisely which part of the ventral PFC must be lesioned in order to get the analogous results. The majority of the anatomical and lesion evidence from both monkeys and humans, however, points to greater posterior DLPFC (areas 8A and posterior 46) involvement in the maintenance of spatial location information and greater posterior ventrolateral PFC (areas 45/12 in monkeys and 45/47 in humans) involvement in the maintenance of nonspatial information.

The results of physiological experiments using singlecell recording in monkeys and functional neuroimaging in humans have been even more controversial, but again, the bulk of the evidence now favors a dorsal/ventral functional topography within the posterior PFC dependent on the type of stimulus features maintained in WM. Individual cells in both the dorsal and the ventral PFC of the monkey can show selectivity for locations, objects, or both, depending on which is task relevant (Rainer et al., 1998a; Rao et al., 1997). Such adaptive coding, however, does not necessarily imply equipotentiality (Duncan, 2001). With a limited number of locations and objects, it is difficult to assess whether there is a difference in the degree of selectivity across different cells or regions of the cortex. It is also not known whether there is a difference between the dorsal and the ventral PFC regarding the timing of the dissociation between the preferred and the nonpreferred stimulus attributes. If such a difference in the time courses exists, it would suggest that this dual selectivity arises from secondary interac- tions within the PFC and that the origins of selectivity for spatial locations or objects arise from anatomically different systems. Functional neuroimaging studies in humans have demonstrated greater activation of both the dorsal and the ventral PFC during both location and object WM tasks, relative to nonmnemonic control tasks (Baker, Frith, Frackowiak, \& Dolan, 1996; D'Esposito et al., 1998; Nystrom et al., 2000; Owen, Evans, \& Petrides, 1996; Owen, Milner, Petrides, \& Evans, 1996; Owen et al.,1998; Postle \& D'Esposito, 1999; Postle, Stern, Rosen, \& Corkin, 2000; Postle, Zarahn, \& D'Esposito, 2000; Sala et al., 2003; Stern et al., 2000). This result has been interpreted by some researchers as evidence for a common neural system for both information types. However, activation of the dorsal PFC during object tasks and the ventral PFC during spatial tasks could reflect several factors. First, there could be incidental processing of irrelevant information. Second, objects may have a distributed representation in WM, including spatial, verbal, and semantic information, as will be discussed below (Sala et al., 2003). In addition, the observed activation could be the result of interactions between dorsal and ventral PFC regions, as will be discussed below (Sala, 2003). These factors, as well as a lack of sufficient statistical power, have likely contributed to the difficulties of several imaging studies in humans to find dor$\mathrm{sal} / \mathrm{ventral}$ differences in the patterns of activation within the PFC for these two types of tasks (Baker et al., 1996; Belger et al., 1998; McCarthy et al., 1996; Nystrom et al., 2000; Owen, Milner, et al., 1996; Owen et al., 1998; Postle \& D’Esposito, 1999; Postle, Zarahn, \& D’Esposito, 2000; Smith et al., 1995).

Other single-cell physiology and neuroimaging studies have provided more convincing evidence in favor of a dorsal/ventral functional topography for location versus object WM. Experiments by Goldman-Rakic and her colleagues have consistently revealed differences in the selectivity of cells in the inferior convexity versus those in the posterior part of the principal sulcus (see the review in Levy \& Goldman-Rakic, 2000). Neurons in the inferior convexity usually respond best to stimuli presented foveally and respond selectively to textures, shapes, and faces more often than do cells around the principal sulcus (Ó Scalaidhe et al., 1997, 1999; Wilson et al., 1993). Principal sulcus neurons, on the other hand, are well known to have spatial mnemonic receptive fields, including many cells that respond best to stimuli presented peripherally (e.g., Funahashi et al., 1989; Fuster \& Alexander, 1971; Kubota \& Niki, 1971). Several neuroimaging studies in which relative amounts of activation have been compared during closely matched location and object WM tasks, rather than relying on an arbitrary baseline comparison (Gusnard \& Raichle, 2001; Stark \& Squire, 2001), have shown a double dissociation (Arnott, Grady, Hevenor, Graham, \& Alain, in press; Courtney, Petit, Maisog, Ungerleider, \& Haxby, 1998; Courtney, Ungerleider, Keil, \& Haxby, 1996; Munk et al., 2002; 
Rämä et al., 2004; Sala, 2003; Sala et al., 2003). If one also considers experiments that have included WM only for a single stimulus feature in isolation, however, a functional dissociation is also apparent. The ventral PFC, such as the inferior and middle frontal gyri, is most consistently activated during WM for faces (Courtney et al., 1998; Courtney et al., 1996, 1997), objects other than faces (Belger et al., 1998; McCarthy et al., 1996; Munk et al., 2002; Sala, 2003; Sala et al., 2003; Smith et al., 1995), and verbal information (Awh et al., 1996; Fiez et al.,1996; Gruber \& von Cramon, 2003; Jonides et al., 1997; Paulesu, Frith, \& Frackowiak, 1993; Prabhakaran, Narayanan, Zhao, \& Gabrieli, 2000; Rämä, Sala, Gillen, Pekar, \& Courtney, 2001; Smith, Jonides, \& Koeppe, 1996). The more dorsal prefrontal cortex, specifically the posterior part of the superior frontal sulcus, has been most consistently activated during spatial WM tasks (Baker et al., 1996; Carlson et al., 1998; Courtney et al., 1996, 1998; Glahn et al., 2002; Jonides et al., 1993; Mellet et al., 1996; Nystrom et al., 2000; Owen, Evans, \& Petrides, 1996; Owen, Milner, et al., 1996; Petit et al., 1996; Rowe, Toni, Josephs, Frackowiak, \& Passingham, 2000; Smith et al., 1996; Smith et al., 1995; Zarahn, Aguirre, \& D'Esposito, 1999).

Although most research on WM has involved tasks in which visual stimuli have been used, there have been a few recent studies in which WM for the locations or the identities of auditory stimuli has been compared. Neuroanatomical studies in monkeys indicate that, as in the visual system, there are two functionally dissociable pathways in the auditory system and that these pathways appear to have different projection zones within the PFC (Rauschecker \& Tian, 2000; Romanski et al., 1999). Results from neuroimaging studies so far indicate that auditory WM shows a similar dorsal/ventral functional topography within the PFC (Alain, Arnott, Hevenor, Graham, \& Grady, 2001; Arnott, Binns, Grady, \& Alain, 2004; Arnott et al., in press; Rämä et al., 2004). Spatial location tasks activate the superior frontal sulcus more than do identity tasks, whereas identity tasks show greater activation of the posterior ventral frontal cortex. The anatomical projections (Poremba et al., 2003; Romanski et al., 1999) and the regions of activation during these WM tasks appear to be similar, although not identical, for visual and auditory stimuli (Rämä \& Courtney, 2005). Thus, anatomical and physiological evidence points to a modality-independent dorsal/ventral functional topography within the posterior PFC that is dependent on the stimulus features (e.g., location, object identity, or verbal) being maintained.

What versus where or nonspatial versus spatial? Despite this growing body of evidence for a dissociation between the neural system enabling WM for objects versus that enabling WM for locations, there remain questions regarding the nature of this dissociation. Statistical power and choice of an fMRI baseline task does not seem to account entirely for the seemingly contradictory collection of data. Distinctions between spatial and verbal (phonological) WM (e.g., Gruber \& von Cramon, 2003; Smith et al., 1996) appear to be more robust than distinctions between spatial and object WM. Part of the explanation may lie in the representation of object identity in WM. Certain aspects of the representation of object identity may be mediated through the dorsal stream. This appears to be true in both the visual system during perceptual tasks and the PFC during WM tasks.

Neuroimaging studies of object and spatial WM that failed to find a double dissociation generally have used geometric shapes, patterns, or novel three-dimensional objects (Nystrom et al., 2000; Owen et al., 1998; Pollmann \& von Cramon, 2000; Postle \& D'Esposito, 1999; Postle, Stern, et al., 2000). Some of the first neuroimaging evidence for a dissociation between object and location WM came from studies in which faces were used as the objects to be remembered (Courtney et al., 1998; Courtney et al., 1996). In a study by Sala et al. (2003), activation patterns were directly compared during WM tasks for spatial locations, house identity, or face identity. That study showed a double dissociation within the PFC for object versus location WM for both faces and houses. However, the magnitude of the dissociation within the superior frontal sulcus was smaller for houses versus locations than for faces versus locations. In addition, Sala and colleagues performed a dual-task interference experiment outside of the scanner, in which subjects performed a delayed recognition task for either two or four locations during the delay period of a delayed recognition task for either faces or houses. The load effect on accuracy for the spatial WM task was greater while house identity was also maintained than while face identity was also maintained. Both the neuroimaging and the behavioral results of this study indicate that spatial WM shares more neural resources with house WM than with face $\mathrm{WM}$. These results suggest that object representation in WM may be distributed across both dorsal and ventral pathways, with some types of objects containing more spatial information (such as the spatial relationships among parts of the object) than others do. Consistent with this view, patients with bilateral parietal damage resulting in Balint syndrome also have difficulty perceiving the spatial organization of features within an object (Robertson, Treisman, Fiedman-Hill, \& Grabowecky, 1997). In addition, a study of long-term memory retrieval of object shapes, sizes, and colors demonstrated greater dorsal stream activity for shape and size retrieval than for color retrieval (Oliver \& Thompson-Schill, 2003). Furthermore, preliminary data from our laboratory indicate a dorsal/ventral double dissociation during WM delays for shapes versus colors (Yee, Sala, \& Courtney, 2003) and for fractal-like patterns versus legal nonwords (Roe, Debruin, Roth, \& Courtney, 2003). Thus, object features that have a spatial-like aspect, such as houses, shapes, and fractal-like patterns, may preferentially activate the more dorsal PFC, whereas object features that 
do not, such as colors and verbal information, may preferentially activate the more ventral PFC.

Another possible "spatial" aspect to previous studies of object WM is temporal order. When maintenance of temporal order is required by the task, such as is the case with the commonly used $n$-back task, subjects may recode the temporal order of the objects into a spatial code (i.e., locations) for visualization during rehearsal. This may be another contributing factor to dorsal stream activation and load effects during object WM tasks (e.g., Nystrom et al., 2000).

Verbal and semantic features of objects. The representation of object identity may also be distributed in terms of the verbal and semantic information associated with the visual image of the objects. Familiar objects have a name and semantic information associated with them, and this information may be maintained in WM together with, or instead of, the visual image of the objects (e.g., Rämä et al., 2001). Naming pictures of familiar tools activates parietal and premotor regions more than does naming pictures of animals (Martin, Wiggs, Ungerleider, \& Haxby, 1996), suggesting that semantic knowledge regarding the use of those tools is automatically retrieved during recognition. Similarly, Mecklinger, Gruenewald, Besson, Magnié, and von Cramon (2002) found that WM for manipulable objects activates premotor and parietal cortices more than does WM for nonmanipulable objects. Subjects frequently report using verbal description rehearsal strategies even for tasks in which novel, trial-unique objects are used, and even when such strategies prove to be ineffective. Some studies have reported a right/left dissociation regarding the magnitude of activation in the PFC for spatial versus object WM tasks either in addition to (Sala, 2003; Smith \& Jonides, 1999) or instead of (D'Esposito et al., 2000) a dorsal/ventral dissociation. This left lateralization for object WM could be due to verbal rehearsal strategies (Rämä et al., 2001). Studies of spatial WM in which regular grids of possible locations are used likely also include some activation attributable to verbal rehearsal strategies, leading to overlap in the pattern of activation with object WM tasks.

Integration of objects and their locations. WM for individual object features, such as color or shape, can be influenced by the spatial relationships among multiple objects in the visual field (Jiang, Olson, \& Chun, 2000). Spatial relationships can also be used to create more efficient representations of the spatial locations themselves by reorganizing the individual locations into groups. Encoding of stimulus sequences that contain pauses and patterns conducive to the formation of structured groups of locations in WM lead to greater activation in the lateral PFC (BAs 9, 44, 45, and 47), as compared with encoding of unstructured sequences (Bor, Duncan, Wiseman, \& Owen, 2003). Object features can also be bound together in WM to form integrated representations of objects in particular locations, a process that may enable a greater number of features to be maintained (Luck \&
Vogel, 1997). Such binding of an object or its features to a location is not obligatory, however, and appears to require selective attention to be achieved (Wheeler \& Treisman, 2002). When an object is selectively attended, however, both the relevant and the irrelevant features of that object are processed to a greater degree than those of an unattended object (Duncan, Humphreys, \& Ward, 1997; O’Craven, Downing, \& Kanwisher, 1999; Schoenfeld et al., 2003). Sala (2003) used a speeded discrimination task embedded within the delay period of a WM task to probe the representation of the information maintained in the memory buffer under different task conditions. He demonstrated that the task instructions and whether the WM recognition test conditions make the binding of an object to a location advantageous or disadvantageous to task performance affect whether or not the representations in WM of an object and a location will be conjoined.

Physiological results also suggest that the representation of an object, its location, or the relationship between the two in WM depends on the task demands. In addition to the studies reviewed above regarding selective maintenance of either an object or its location, a few recent studies have specifically addressed how neural activity changes when subjects must remember the conjunction of an object and its location. Two fMRI studies have suggested that activation of additional frontal cortical regions, other than those required to maintain each stimulus feature alone, might mediate the interactions required to create such an integrated representation (Munk et al., 2002; Prabhakaran et al., 2000). However, the regions showing such additional activation were not the same across the two studies. In two other fMRI experiments (Sala, 2003) no additional regions of activation were found, but instead, activation was restricted to the same set of dorsal and ventral prefrontal regions as were active for maintaining either the locations or the object identities alone. In those experiments, the magnitude of activation in the superior frontal sulcus was greatest for location WM, least for object WM, and in between for the conjunction of objects and their locations. Conversely, the ventral PFC had the greatest activation for object $\mathrm{WM}$ and the least for location WM, but again the activation for the conjunction task was in between. Thus, there was no evidence that the representation of the combination of an object and its location was the same as the sum of the representations when either objects or locations alone were maintained. There was also no evidence for a separate cortical area that represented the relationship between the objects and their locations. Instead, these results suggest that an object-in-its-location has a different, perhaps more selective, representation within the same regions that represent objects and locations separately when the relationship between the two is not relevant to the task.

In nonhuman primates, when both an object and its location are task relevant, individual cells in both the dorsal and the ventral PFC are selective for both object identity and location, showing their greatest level of activity 
when both the object and the location of the stimulus match those of the cell's preferred stimulus (Rainer et al., 1998b). When monkeys must switch from remembering an object to remembering a location, an individual PFC cell can also switch its selectivity immediately (Rao et al., 1997). Individual cells that do not initially have dual selectivity can also develop a similar response profile through training (Asaad, Rainer, \& Miller 1998; Murray, Bussey, \& Wise, 2000). Similar to the neuroimaging and behavioral results described above, these single-cell physiology results support the idea that the same population of cells can interact in different ways in order to produce different representations of relevant information. These multiplexed, distributed representations are likely the result of secondary interactions among dorsal and ventral posterior PFC regions. The strength of these interactions is likely to be task dependent, as are the interactions among other PFC regions.

Changing the representation of information in WM. The studies reviewed above indicate that the representation within WM of features of recently presented stimuli varies according to the task requirements. Posterior regions of the PFC are involved in maintaining, for example, the representation of nonspatial object features, the conjunctions of features that make up objects, their locations, the spatial relationships among objects or parts of an object, and the relationship between an object and its location. In neuroimaging studies, if the tasks to be compared do not vary in any way other than the type of stimulus features to be maintained, domain-dependent differences in activation in more anterior portions of the PFC (e.g., areas 46, 9, and 10) are frequently not observed. Activation differences in other PFC regions are more likely to be observed when new representations must be created by integrating the stimulus feature information with other types of information, such as task instructions. One example of a task requiring such a transformation of information is the alphabetize task used by D'Esposito et al. (1999). In this study, maintenance of letters in WM resulted in less activation of the DLPFC than did manipulation of those same items into a different (alphabetical) spatiotemporal order. Owen and his colleagues also found greater activation of the DLPFC in a task that required manipulation of spatial information (Owen, Evans, \& Petrides, 1996).

A study by Hoshi, Shima, and Tanji (1998) required monkeys to reach for an object on the basis of either its shape or its location. They found that some cells in the DLPFC were selective for stimulus features (circle vs. triangle), whereas other cells were selective for the type of task (shape vs. location). Although this study did not require the animals to use the task information to change the representation of the stimulus information, it suggests that the PFC can maintain both stimulus features and task rules in separate neuronal populations. Interactions among different PFC populations could integrate task information with stimulus information in order to transform the stimulus information into a representation that is more directly related to the required behavioral response. These transformations are likely similar to changes in representation observed in other brain areas, such as within sensory system hierarchies or from spatial WM in the PFC to a motor sequence plan in the premotor cortex (Ohbayashi, Ohki, \& Miyashita, 2003). When the task instructions are to maintain the same information, rather than change it, and there are other distracting inputs that could undesirably change the representation of that information, the task instructions maintained within a region such as BA 46 could serve to make the representation of stimulus features more distraction resistant (Sakai, Rowe, \& Passingham, 2002).

Because engaging cognitive processes, such as selection or manipulation, would involve both the representation and the use of abstract information, it is difficult (but not impossible) to disentangle process engagement from rule representation when interpreting the patterns of fMRI activation observed during different tasks. Data do not currently exist to answer this question definitively. However, an information representation model could explain the current data, such as that from the alphabetize and selection experiments, in the following way. An alphabetize rule contains more information than remember the letters in forward order, because one must represent not just the instructions, but also the order of the letters in the alphabet and, perhaps, a strategic procedure (as represented by a structured collection of rules) for carrying out the transformation. This could lead to increased activation due to an abstract information representation load effect. In addition, if processes are implemented via interactions among the PFC regions that represent the information necessary for a certain process, greater synaptic inputs to and outputs from those regions will result in greater fMRI activation during the engagement of that process. The PFC stores internal mnemonic representations that interact with, but are different from, those stored in posterior cortical regions (e.g., Freedman et al., 2003; Miller et al., 1996). These PFC representations presumably have both permanent and dynamic aspects. The structure of the PFC is determined through development and experience and, thus, is itself a representation of this information. The active state of these networks provides additional information that may change quickly in response to newly gathered information. The possible active states depend on the current structure of the PFC. The most anterior portions of the PFC contain the most integrated, abstract representations of all the available information and sit at the top of this proposed hierarchy that biases the outcome of competitions for representation through both serial and parallel feedback mechanisms both within and beyond the PFC. Miller and Cohen's (2001) proposal that the mechanism of the PFC's influence on perception and behavior is modulatory, rather than arising from the transfer of information from the PFC to other brain regions, should be extended to include the influence of some regions of the PFC on other regions of the PFC and on the 
functional connectivity among PFC regions. Task context and individual strategies will influence what other kinds of information will be selected and/or maintained and which will not. Thus, not only would the PFC modulate the strength of associations between stimuli and appropriate responses, but also the anterior PFC could modulate the strength of the associations among representations being maintained by the posterior PFC.

Representation of context, instructions, rules, and motivation. It is clear, therefore, that representation of task rules is necessary to transform sensory information in $\mathrm{WM}$ to a representation that is more appropriate for the behavioral goals, and individual cells in the PFC (particularly within area 46) appear to be selective for abstract task rules (e.g., Hoshi et al., 1998; Wallis, Anderson, \& Miller, 2001; White \& Wise, 1999). The next question is how the representation of an abstract rule may be created. Multiple sources of information must be integrated, including, at least, the association between a stimulus and a behavior and the reward history related to that association. There may also be intermediate steps required to complete the task correctly. The individual may need to access stored knowledge in order to correctly interpret verbal or symbolic instructions and convert that information into a strategy for performance. The inputs to and the structure of the PFC could, in theory, enable all these types of information to be integrated into a single abstract representation of the "rules of the game" (Miller \& Cohen, 2001). However, each of these types of information may be more or less important to the current situation, and each of these types of information may also be represented within different regions of the PFC, due to different anatomical patterns of inputs from other neural systems. This functional topography of the representation of the information relevant to the current context and task instructions could lead to differences in neuroimaging activation patterns for different tasks, not because of the different processes involved in the tasks, but because of the different types of information required by each task.

Even in the earliest fMRI studies of sustained activity in the PFC during WM tasks, it was clear that there were functional differences among multiple $\mathrm{PFC}$ regions. Cohen et al. (1997) used a delayed $n$-back task and demonstrated that different regions both within and outside of the PFC demonstrated a main effect of time, a main effect of WM load, and/or an interaction between time and load. These results suggested differential involvement of these regions in the encoding/updating and maintenance phases of the task. Courtney et al. (1997), using a delayed recognition task, also demonstrated different time courses of fMRI activity among three separate PFC regions. These data suggested a hierarchical organization of the PFC. The posterior PFC regions (BAs 44/45 and 46) responded to the presentation of the sample stimulus and then sustained that activation during the delay period, suggesting an involvement in maintenance of the stimulus representation. A more anterior region (in BA 10), however, showed a minimal response to sample stimuli and no response to control task stimuli but, instead, showed a robust response only during the delay period, suggesting a role in retrieval and rehearsal after the stimulus was removed from view.

These results are consistent with more recent data obtained when experimental tasks specifically designed to test for a hierarchical organization were used (Koechlin, Ody, \& Kouneiher, 2003). The cascade model proposed in conjunction with that study describes three stages related to the control of behavior in response to stimulus, contextual, and episodic information. Koechlin et al. stated that "each stage maintains active representations that are controlled by higher stages and that exert control on representations in lower stages" (pp. 1184). Fuster's (2001) model of prefrontal organization is also hierarchical in that progressively more anterior areas "support functions that are progressively more integrative." The present model combines these two concepts but emphasizes the representation of different types of information in different regions of the PFC, along both anterior-posterior and dorsal-ventral dimensions. The present model also emphasizes the idea of dynamic interactions among these regions that transform information in one region according to the needs indicated by the representation of other kinds of information in other PFC regions. These interactions may be feedforward, feedback, or within a hierarchical level.

Other studies have also suggested that the most anterior portions of the PFC represent the most abstract aspects of task-related information. The anterior PFC has been implicated in many different functions, including dual-task performance, task switching, subgoal processing, reasoning, and selective long-term memory retrieval (see a review in Ramnani \& Owen, 2004). What all of these tasks appear to have in common is the need for supramodal representation of context, instruction cues, rules, and motivation. It is this kind of information that must guide the formation of the most appropriate representation of more specific types of information (such as stimulus features) maintained via more posterior PFC regions. Sakai and Passingham (2003) demonstrated that the anterior PFC is active after an instruction cue but before task execution (indicating an involvement in task set). The amount of activation within the anterior PFC was not dependent on whether the subjects were preparing to perform a spatial versus a verbal WM task. The correlation between that anterior prefrontal region and domaindependent posterior PFC regions, however, was dependent on which type of stimuli would soon be task relevant. This supports the idea that the PFC may be a source of biasing signals that affect more than the function of sensory and motor areas (Sala, 2003). These biasing signals may also work within the PFC, influencing which items will be maintained and which inhibited.

Consistent with a study by Koechlin et al. (2003) that suggested that the anterior PFC maintains episodic context information, the anterior PFC may represent current 
goals and, therefore, maintain task set for the current trial under conditions that sometimes require task switching. The DLPFC (BA 46), on the other hand, may represent the task rules and, therefore, be involved in maintenance of task set when the goals or the instructions do not change but there are distracting, competing stimuli. Sakai et al. (2002) found that BA 46 activation was associated with increased correlation between the superior frontal sulcus and the parietal cortex. The strength of this interaction was correlated with improved performance only under conditions of distraction.

There are many other types of information that likely are included in PFC representations. Individuals obtain feedback when observing their own behavior, either visually or through somatosensory input. This information may be represented in or near BA 9, since lesions of this region disrupt performance on self-monitoring tasks (Petrides, 1995a, 1995b). Information regarding one's own and others' cognitive, affective, and motivational states may be represented in the medial PFC (Gallagher \& Frith, 2003; Schmitz, Kawahara-Baccus, \& Johnson, 2004). Long-term experience could also be represented in the PFC via either explicit or implicit knowledge that is sent to the PFC from other brain areas, including semantic or episodic memories, reward history, or behavior patterns established through repeated performance of particular tasks. Representations of such long-term knowledge may also be "permanently" stored in the PFC, not just as part of the temporary activated state that influences other areas. Long-term memories are thought to be stored, in some way, in the neocortex (for a review, see Eichenbaum, 2000). This cortical representation of stored knowledge likely includes the PFC (Maviel, Durkin, Menzaghi, \& Bontempi, 2004). Thus, the PFC contains both stable and dynamic representations of information (see also Fuster, 2001).

Interactions of information type, processes, and tasks. Domain specificity and processing specificity are not mutually exclusive organizational principles (see also Curtis \& D'Esposito, 2003; Petrides, Alivisatos, \& Frey, 2002). The hypothesis proposed here is not that processing differences among PFC (or other brain) regions do not exist but, rather, that the cortical regions are organized according to the information represented within those regions. Processing is achieved through interactions among these brain regions, and those interactions may be different, depending on the type of information involved. Some research that has provided evidence for different neural systems for WM maintenance of different types of stimulus features has also demonstrated that the different information types are processed differently within their respective systems. For example, although work by Goldman-Rakic and her colleagues has demonstrated that both dopamine (Williams \& Goldman-Rakic, 1995) and serotonin (Williams, Rao, \& Goldman-Rakic, 2002) affect spatial tuning of the cells in the DLPFC that demonstrate sustained activity during delayed response tasks, dopaminergic and serotinergic manipulation ap- pears to have differential effects on the performance of tasks usually associated with the DLPFC versus the ventral and orbital PFC (Robbins, 2000). In addition, a genetic study of monozygotic and dizygotic twins indicated that whereas a large portion of the genetic variation accounted for WM capacity measures, independently of information type, there were also genetic components that were specific to verbal versus spatial performance (Ando, Ono, \& Wright, 2001). That the neural systems subserving WM for different types of information can be differentially affected by chemical and genetic factors suggests that the internal circuitry of these networks is different. Thus, increasing WM capacity might not be the only advantage of maintaining different types of information via separate systems. These results suggest that different types of information may require different types of representations, different processes to transform those representations, and different interactions with other systems, such as the motor system or the medial temporal lobe. Thus, WM for locations and objects appears to be achieved through parallel, but not identical, neural systems.

Lesion and neuroimaging studies also provide evidence for interactions among information type, processing type, and task demands. Cognitive neuroscience experiments in either human or nonhuman primates, using either physiological or lesion methods, ultimately must rely on manipulations of the tasks that the subjects are to perform. These tasks require multiple computational processes. Even relatively simple tasks that appear to differ only in the type of information used may also apply different types of computations to that information. Johnson, Raye, Mitchell, Greene, and Anderson (2003) compared fMRI activation patterns in two experiments in which very simple tasks were used in an attempt to minimize the number of cognitive processes involved. Experiment 1 contained three task conditions in which three stimulus types (words, objects, and patterns) were used. Experiment 2 contained four task conditions in which two stimulus types (words and objects) were used. They found that whether there was a significant difference in activation between stimulus types depended on which task conditions were considered. Similarly, whether there was a significant difference in activation between task conditions depended on which stimulus types were used. The present framework suggests two, not mutually exclusive, interpretations of these data. First, both objects and words may have distributed representations with visual and verbal components in each. Thus, whether the process (i.e., task condition) comparisons tapped into common or distinct aspects of these distributed representations would affect whether or not a difference between stimulus types would be observed. Second, even these relatively simple tasks may require representation of additional information beyond the stimuli themselves (e.g., task instructions), and the demand for these other types of information may be different for different task conditions, stimuli, or both. 
Interactions between tasks and information representations may also be observed within the spatial information domain. The same sensory input can be transformed in multiple ways, by integrating that information with additional information from other sources. The computational processes required to create each of those representations could also differ. In the visual system, on the basis of neuropsychological evidence, Goodale and Milner (1992) suggested that the dorsal stream is concerned primarily with motor action and proposed that spatial perception that is independent of action is represented in the ventral stream, although other evidence contradicts this view and supports the idea that spatial perception that is independent of action also depends on parietal areas (e.g., Courtney et al., 1998; Ungerleider \& Haxby, 1994). Information about the locations of objects relative to one's own body is clearly necessary for planning motor actions related to those objects, such as reaching and grasping. Indeed, perhaps even when an explicit motor action is not required or desirable for a specific task, the spatial location of an object may normally be partially coded in terms of the motor movements required to orient the body toward that object. Neuroimaging and neuropsychological evidence indicates that there are dissociable systems within the parietal cortex for reaching movements, grasping movements, and perception of spatial information independent of motor movement (for a review, see Creem \& Proffitt, 2001). The distinction between these regions may be based primarily on the spatial frame of reference. For example, different regions may encode spatial information in egocentric, allocentric, or object-centered coordinates, each of which is differentially suited for various types of tasks. This concept is similar to the one proposed here for the PFC, in that the types of processes performed by each part of the parietal cortex may be similar, but these processes are acting upon different types of information, integrating visual input with somatosensory feedback and motor plans and, thus, are more or less important for different types of tasks. The role of the parietal cortex, not only in spatial processing, but also in attentional control and updating of WM, discussed below, suggests another way in which stimulus feature type and cognitive processing may interact. Task repetition, task switching, and changes in attentional demands may have differential effects on spatial versus object WM tasks because of the interaction between selective attention and spatial perceptual processing (Sayala, Sala, \& Courtney, 2004). Thus, there appear to be interactions between information type and processing (again, defined as computations and interactions that affect the representation and use of information) both between and within the neural systems for spatial and nonspatial WM.

\section{Control of Access to Awareness and Working Memory}

The information represented in the PFC appears to control attention through interactions with the parietal cortex.
Interactions between the parietal cortex and sensory processing areas appear to enable the information represented in the parietal cortex to play an important role in controlling the influence that sensory information will have on the rest of the system. This control appears to extend beyond defining the spatial locus of attention. Tasks that appear to involve only nonspatial stimulus feature information, such as color, activate the parietal cortex more than do tasks involving the same stimuli at the same spatial location and involving the same motor response demands, but with fewer cognitive control demands (Claeys et al., 2004; Wojciulik \& Kanwisher, 1999). Not only do shifts of attention from one spatial location to another activate the parietal and superior frontal cortices (e.g., Beauchamp, Petit, Ellmore, Ingeholm, \& Haxby, 2001; Bisley \& Goldberg, 2003; Corbetta \& Shulman, 2002; Hopfinger, Buonocore, \& Mangun, 2000; Vandenberghe, Gitelman, Parrish, \& Mesulam, 2001; Yantis et al., 2002), but so do shifts of attention between two spatially superimposed objects (Serences, Schwarzbach, Courtney, Golay, \& Yantis, 2004) or between two object features, such as color and motion (Liu, Slotnick, Serences, \& Yantis, 2003).

The information access role of the parietal cortex is also not limited to attention for the purpose of immediate perceptual processing. Task switching has frequently been observed to activate the parietal cortex and various regions of the PFC (e.g., Brass \& von Cramon 2004; Braver, Reynolds, \& Donaldson, 2003). Similarly, a recent experiment with monkeys has demonstrated that many cells in a section of the cortex in the intraparietal sulcus and the angular gyrus respond selectively according to changes in the task rules, independently of motor and spatial aspects of the task (Stoet \& Snyder, 2004). Furthermore, although maintenance of the identity of an object in WM involves primarily the ventral prefrontal and occipitotemporal cortices (as described above), updating the information stored in WM by replacing the old object with a new one transiently activates parietal, dorsolateral, and dorsomedial prefrontal regions (Roth, Serences, \& Courtney, 2004). In this study, all the objects were presented foveally and had to be attended to in order to decide whether the current stimulus matched the current sample stimulus being held in WM. The subjects were occasionally cued to discard the current sample stimulus and to maintain the subsequent stimulus as the new sample in WM. Activity during these update events was compared with that for events that included a similar cue stimulus that instructed the subjects to continue to maintain the old sample stimulus. In this study, there was no change in the spatial locus of attention, no change in the type of stimuli to be attended, and no change in the overall task instructions. The only change was the need to temporarily grant access into the WM storage buffer.

It is unclear how a brain region that is known to represent primarily spatial information could facilitate objectbased attentional selection and access to object WM. A clue lies in the proposal by Deneve and Pouget (2003) 
that some regions of the parietal cortex may compute basis functions derived from a combination of retinotopic spatial information, object orientation, and taskrelated signals. Their model appears to account for objectcentered neglect symptoms in some patients with parietal damage and single-cell recording data (for a review, see Olson, 2003), without requiring an explicit representation of object-centered coordinates. Thus, perhaps the same types of computations could achieve attentional selection of an object as those that achieve attentional selection of a spatial location. The primary difference between objectbased and space-based attentional selection, then, would be whether the set of attentional biases acts upon an egocentric representation of space or an object-based representation. The regions of the parietal cortex that respond transiently when a person shifts spatial-, object-, or featurebased attention are quite superior and medial (Liu et al., 2003; Serences et al., 2004; Yantis et al., 2002). Thus, it appears that interactions among these parietal areas, the PFC, and sensory systems implement the effects of biasing signals from the PFC on either object- or spacebased representations in other portions of the parietal cortex. The parietal cortex may represent the relationship between the information represented in the PFC and current or expected sensory information.

Feedback signals from the PFC have long been thought to set up the pattern of relative bias signals that results in certain objects or locations winning the competition for representation (Desimone \& Duncan, 1995). A study by Bisley and Goldberg (2003) suggests that each location represented in area LIP in the monkey parietal cortex can independently receive an attentional biasing signal that changes the activation level of cells with receptive fields in that location. The information that wins access to the limited capacity systems of awareness and/or WM has the greatest relative amount of activity, rather than an absolute amount of activity over some threshold. In this study, regions of space that remained task relevant continued to maintain an elevated level of activation, despite a shift of attention (measured behaviorally) to the location where a distracting stimulus briefly appeared. When the activity in the LIP related to the distracting stimulus subsided, attention shifted back to the task-relevant location, which then had relatively the highest level of activity.

Stimuli compete for access to both awareness and WM. The Roth et al. (2004) study described above suggests that there may be a different set of competitive interactions that determine access to object WM from those that determine attentional priority for immediate perceptual processing, because the region of the parietal cortex activated during updating of WM was different (more lateral and inferior in and around the angular gyrus) from the regions activated by shifts of either object-based (Serences et al., 2004) or feature-based (Liu et al., 2003) attention. In these studies, the subjects shifted their attention on the basis of instructional cues. WM and attentional set (i.e., WM for certain task requirements) are known to influence which stimuli will capture attention without an explicit instruction or intention to attend to those stimuli (e.g., Awh, Jonides, \& Reuter-Lorenz, 1998; Downing, 2000; Sala, 2003). In a study by Serences et al. (in press), subjects searched for a red colored target in a rapid serial visual presentation stream of multicolored letters; target-colored (i.e., red) distractors presented in the periphery disrupted target discrimination performance, but nontarget colored distractors did not. Targetcolored distractors also activated the temporoparietal junction, the intraparietal sulcus, and the PFC more than did nontarget colored distractors. Sala used a speeded discrimination task embedded within the delay period of a WM task to demonstrate that the information maintained in WM affects which stimuli will capture attention and, thus, the speed of perceptual processing. Locations, objects, or their conjunction could independently bias the capture of attention during the discrimination task, depending on which stimulus feature or features were currently relevant to the WM task.

Taken together, these results on attentional control, task-switching, and updating WM suggest that interactions between the parietal cortex and sensory processing regions result in the gating of information according to the attentional priority maps that are established through interactions between the PFC and the parietal cortex. The regions of the parietal cortex that contain these priority maps that result in the selection of items may be different for perceptual processing versus WM maintenance and may be different according to whether the selection is object or location based. In either case, new information will enter WM and awareness only when either it is relevant (in either a direct or an indirect way) to the current contents of WM (broadly defined, including goals and task requirements) or it is salient enough to "break through" the attentional filter.

\section{Conclusions}

The functional organization of the PFC, like that of the rest of the brain, appears to be based primarily on the type of information represented within each cortical area. The PFC appears to have a hierarchical organization, with progressively more anterior regions maintaining progressively more integrated and abstract representations of relevant information. The posterior PFC has a dorsal/ventral spatial/nonspatial functional topography and is primarily involved in the maintenance of representations of locations and other spatial information, nonspatial object features, and verbal information. The DLPFC (approximately BA 46) appears to represent the current task requirements and influences the representations in the posterior PFC and perceptual areas by modulating interactions among these regions. The most anterior portions of the PFC (such as areas 9 and 10) appear to maintain information regarding the individual's current cognitive and environmental context and goals.

The results reviewed here suggest that attention and cognitive control are emergent properties of information representation in WM. In this view, processes are transfor- 
mations of information from one representation to another. Thus, processes may exist only as interactions between brain regions that store different kinds of information. Processes, independent of information type, may not be localizable to individual brain regions. The resolution of competition for representation throughout the brain results in the current attentional or cognitive state, the stimulus features maintained in WM, and the "selection" of particular perceptual information or the "selection" of one motor behavior over another. Thus, all "decisions" are the result of the resolution of competition due to biases created by the accumulation and integration of all the relevant information. In this framework, there is no need to invoke a homunculus that creates separate abstract "goals" and actively "directs" attentional and response selection. The integrated representation of information (which includes current and future needs and knowledge of previous rewards and punishments), in a sense, creates the "goals."

\section{REFERENCES}

Alain, C., Arnott, S. R., Hevenor, S., Graham, S., \& Grady, C. L. (2001). "What" and "where" in the human auditory system. Proceedings of the National Academy of Sciences, 98, 12301-12306.

ANDO, J., ONO, Y., \& WRIGHT, M. J. (2001). Genetic structure of spatial and verbal working memory. Behavior Genetics, 31, 615-624.

Arnott, S. R., Binns, M. A., Grady, C. L., \& Alain, C. (2004). Assessing the auditory dual-pathway model in humans. NeuroImage, 22, 401-408.

ARNotT, S. R., Grady, C. L., Hevenor, S. J., Graham, S., \& Alain, C. (in press). The functional organization of auditory working memory as revealed by fMRI. Journal of Cognitive Neuroscience.

AsaAd, W. F., Rainer, G., \& Miller, E. K. (1998). Neural activity in the primate prefrontal cortex during associative learning. Neuron, 21 , 1399-1407.

AwH, E., JoNides, J., \& Reuter-Lorenz, P. A. (1998). Rehearsal in spatial working memory. Journal of Experimental Psychology: Human Perception \& Performance, 24, 780-790.

Awh, E., Jonides, J., Smith, E. E., Schumacher, E. H., Koeppe, R. A., \& KaTZ, S. (1996). Dissociation of storage and rehearsal in verbal working memory: Evidence from positron emission tomography. Psychological Science, 7, 25-31.

BADDELEY, A. D., \& HITCH, G. J. (1974). Working memory. In G. Bower (Ed.), The psychology of learning and motivation (pp. 47-90). San Diego: Academic Press.

BAdDELEY, A. D., \& LogIE, R. H. (1999). Working memory: The multiplecomponent model. In A. Miyake \& P. Shah (Eds.), Models of working memory: Mechanisms of active maintenance and executive control (pp. 28-61). Cambridge: Cambridge University Press.

Baker, S. C., Frith, C. D., Frackowiak, R. S., \& Dolan, R. J. (1996). Active representation of shape and spatial location in man. Cerebral Cortex, 6, 612-619.

Barbas, H., \& Pandya, D. N. (1989). Architecture and intrinsic connections of the prefrontal cortex in the rhesus monkey. Journal of Comparative Neurology, 286, 353-375.

BAUER, R. H., \& FUSTER, J. M. (1976). Delayed-matching and delayedresponse deficit from cooling dorsolateral prefrontal cortex in monkeys. Journal of Comparative \& Physiological Psychology, 90, 293302 .

Beauchamp, M. S., Petit, L., Ellmore, T. M., Ingeholm, J., \& HaXby, J. V. (2001). A parametric fMRI study of overt and covert shifts of visuospatial attention. NeuroImage, 14,310-321.

Bechara, A., Damasio, H., Tranel, D., \& Anderson, S. W. (1998). Dissociation of working memory from decision making within the human prefrontal cortex. Journal of Neuroscience, 18, 428-437.

Belger, A., Puce, A., Krystal, J. H., Gore, J. C., Goldman-Rakic, P.,
\& MCCARTHY, G. (1998). Dissociation of mnemonic and perceptual processes during spatial and nonspatial working memory using fMRI. Human Brain Mapping, 6, 14-32.

Bisley, J. W., \& GoldBerG, M. E. (2003). Neuronal activity in the lateral intraparietal area and spatial attention. Science, 299, 81-86.

Bor, D., Duncan, J., Wiseman, R. J., \& Owen, A. M. (2003). Encoding strategies dissociate prefrontal activity from working memory demand. Neuron, 37, 361-367.

Brass, M., \& VON CRAMON, D. Y. (2004). Selection for cognitive control: A functional magnetic resonance imaging study on the selection of task-relevant information. Journal of Neuroscience, 24, 8847 8852.

Braver, T. S., \& Cohen, J. D. (2000). On the control of control: The role of dopamine in regulating prefrontal function and working memory. In S. Monsell \& J. Driver (Eds.), Attention and performance XVIII: Control of cognitive processes (pp. 713-737). Cambridge, MA: MIT Press.

Braver, T. S., Reynolds, J. R., \& Donaldson, D. I. (2003). Neural mechanisms of transient and sustained cognitive control during task switching. Neuron, 39, 713-726.

Carlesimo, G. A., Perri, R., Turriziani, P., Tomaiuolo, F., \& CaltaGIRONE, C. (2001). Remembering what but not where: Independence of spatial and visual working memory in the human brain. Cortex, 37, 519-534.

Carlson, S., MartinkaupPI, S., Rämä, P., Salli, E., Korvenoja, A., \& Aronen, H. J. (1998). Distribution of cortical activation during visuospatial $n$-back tasks as revealed by functional magnetic resonance imaging. Cortex, 8, 743-752.

Cavada, C., \& Goldman-RaKic, P. S. (1989). Posterior parietal cortex in rhesus monkey: II. Evidence for segregated corticocortical networks linking sensory and limbic areas with the frontal lobe. Journal of Comparative Neurology, 287, 422-445.

Claeys, K. G., Dupont, P., Cornette, L., Sunaert, S., van Hecke, P., De Schutter, E., \& Orban, G. A. (2004). Color discrimination involves ventral and dorsal stream visual areas. Cerebral Cortex, 14, 803-822.

Cohen, J. D., Perlstein, W. M., Braver, T. S., Nystrom, L. E., Noll, D. C., Jonides, J., \& SMith, E. E. (1997). Temporal dynamics of brain activation during a working memory task. Nature, 386, 604608.

Constantinidis, C., Franowicz, M. N., \& Goldman-Rakic, P. S. (2001a). Coding specificity in cortical microcircuits: A multipleelectrode analysis of primate prefrontal cortex. Journal of Neuroscience, 21, 3646-3655.

Constantinidis, C., Franowicz, M. N., \& Goldman-Rakic, P. S. (2001b). The sensory nature of mnemonic representation in the primate prefrontal cortex. Nature Neuroscience, 4, 311-316.

Corbetta, M., \& Shulman, G. L. (2002). Control of goal-directed and stimulus-driven attention in the brain. Nature Reviews Neuroscience, 3, 201-215.

Courtney, S. M., Petit, L., Maisog, J. M., Ungerleider, L. G., \& HAXвy, J. V. (1998). An area specialized for spatial working memory in human frontal cortex. Science, 279, 1347-1351.

Courtney, S. M., Ungerleider, L. G., Keil, K., \& Haxby, J. V. (1996). Object and spatial visual working memory activate separate neural systems in human cortex. Cerebral Cortex, 6, 39-49.

Courtney, S. M., Ungerleider, L. G., Keil, K., \& Haxby, J. V. (1997). Transient and sustained activity in a distributed neural system for human working memory. Nature, 386, 608-611.

Creem, S. H., \& Proffitt, D. R. (2001). Defining the cortical visual systems: "What," "where," and "how." Acta Psychologica, 107, 43-68.

Curtis, C. E., \& D'Esposito, M. (2003). Persistent activity in the prefrontal cortex during working memory. Trends in Cognitive Science, 7, 415-423.

Deneve, S., \& Pouget, A. (2003). Basis functions for object-centered representations. Neuron, 37, 347-359.

Desimone, R., \& DunCan, J. (1995). Neural mechanisms of selective visual attention. Annual Review of Neuroscience, 18, 193-222.

D'Esposito, M., Aguirre, G. K., Zarahn, E., BallakD, D., Shin, R. K., \& LEASE, J. (1998). Functional MRI studies of spatial and nonspatial working memory. Cognitive Brain Research, 7, 1-13. 
D’Esposito, M., Postle, B. R., Ballard, D., \& Lease J. (1999). Maintenance versus manipulation of information held in working memory: An event-related fMRI study. Brain \& Cognition, 41, 66-86.

D'Esposito, M., Postle, B. R., \& Rypma, B. (2000). Prefrontal cortical contributions to working memory: Evidence from event-related fMRI studies. Experimental Brain Research, 133, 3-11.

DownING, P. E. (2000). Interactions between visual working memory and selective attention. Psychological Science, 11, 467-473.

DunCAN, J. (2001). An adaptive coding model of neural function in prefrontal cortex. Nature Reviews Neuroscience, 2, 820-829.

DunCan, J., HumphreYs, G., \& Ward, R. (1997).Competitive brain activity in visual attention. Current Opinion in Neurobiology, 7, 255-261.

Eichenbaum, H. (2000). A cortical-hippocampal system for declarative memory. Nature Reviews Neuroscience, 1, 41-50.

Fiez, J. A., Raife, E. A., Balota, D. A., Schwarz, J. P., Raichle, M. E., \& Petersen, S. E. (1996). A positron emission tomography study of the short-term maintenance of verbal information. Journal of Neuroscience, 16, 808-822.

Freedman, D. J., Riesenhuber, M., Poggio, T., \& Miller, E. K. (2003). A comparison of primate prefrontal and inferior temporal cortices during visual categorization. Journal of Neuroscience, $\mathbf{2 3}$, 5235-5246

Funahashi, S., Bruce, C. J., \& Goldman-Rakic, P. S. (1989). Mnemonic coding of visual space in the monkey's dorsolateral prefrontal cortex. Journal of Neurophysiology, 61, 331-349.

Fuster, J. M. (2001). The prefrontal cortex-an update: Time is of the essence. Neuron, 30, 319-333.

Fuster, J. M., \& ALEXANDER, G. E. (1971). Neuron activity related to short-term memory. Science, 173, 652-654.

Fuster, J. M., BAuer, R. H., \& JeRVEY, J. P. (1985). Functional interactions between inferotemporal and prefrontal cortex in a cognitive task. Brain Research, 330, 299-307.

Fuster, J. M., BODNer, M., \& KROGER, J. (2000). Cross-modal and cross-temporal association in neurons of frontal cortex. Nature, $\mathbf{4 0 5}$ 347-351.

GALlaGHer, H. L., \& Frith, C. D. (2003). Functional imaging of "theory of mind." Trends in Cognitive Sciences, 7, 77-83.

Glahn, D. C., Kim, J., Cohen, M. S., Poutanen, V. P., Therman, S., Bava, S., Van ErP, T. G., Manninen, M., Huttunen, M., LonNQvist, J., Standertskjold-Nordenstam, C. G., \& Cannon, T. D. (2002). Maintenance and manipulation in spatial working memory: Dissociations in the prefrontal cortex. NeuroImage, 17, 201-213.

GoldMAN-RAKIC, P. [S.] (1987). Circuitry of primate prefrontal cortex and regulation of behavior by representational memory. In J. M. Brookhart \& V. B. Mountcastle (Series Eds.) \& F. Plum (Vol. Ed.), Handbook of physiology: Section 1. The nervous system: Vol. 5. Higher functions of the brain (pp. 373-417). Washington, DC: American Physiological Society.

GoldMAN-RAKIC, P. S. (1995a). Architecture of the prefrontal cortex and the central executive. In J. Grafman, K. J. Holyoak, \& F. Boller (Eds.), Structure and function of the human prefrontal cortex (Annals of the New York Academy of Sciences, Vol. 769, pp. 71-83). New York: New York Academy of Sciences.

Goldman-RaKic, P. S. (1995b). Cellular basis of working memory. Neuron, 14, 477-485.

Goodale, $\bar{M}$. A., \& Milner, A. D. (1992). Separate visual pathways for perception and action. Trends in Neurosciences, 15, 20-25.

Gruber, O., \& von Cramon, D. Y. (2003). The functional neuroanatomy of human working memory revisited: Evidence from 3-T fMRI studies using classical domain-specific interference tasks. NeuroImage, 19 797-809.

GuSNARD, D. A., \& RAichle, M. E. (2001). Searching for a baseline: Functional imaging and the resting human brain. Nature Reviews Neuroscience, 2, 685-694.

Hopfinger, J. B., BuONOCORE, M. H., \& MANGUn, G. R. (2000). The neural mechanisms of top-down attentional control. Nature Neuroscience, 3, 284-291.

Hoshi, E., SHIMA, K., \& TANJI, J. (1998). Task-dependent selectivity of movement related neuronal activity in the primate prefrontal cortex. Journal of Neurophysiology, 80, 3392-3397.
JiANG, Y., Olson, I. R., \& ChUn, M. M. (2000). Organization of visual short-term memory. Journal of Experimental Psychology: Learning, Memory, \& Cognition, 26, 683-702.

Johnson, M. K., RaYe, C. L., Mitchell, K. J., Greene, E. J., \& ANDERSON, A. W. (2003). fMRI evidence for an organization of prefrontal cortex by both type of process and type of information. Cerebral Cortex, 13, 265-273.

Jonides, J., Schumacher, E. H., Smith, E. E., Lauber, E. J., Awh, E., Minoshima, S., \& Koeppe, R. A. (1997). Verbal working memory load affects regional brain activation as measured by PET. Journal of Cognitive Neuroscience, 9, 462-475.

Jonides, J., Smith, E. E., Koepre, R. A., Awh, E., Minoshima, S., \& Mintun, M. A. (1993). Spatial working memory in humans as revealed by PET. Nature, 363, 623-625.

Koechlin, E., Ody, C., \& KoUNEIHER, F. (2003). The architecture of cognitive control in the human prefrontal cortex. Science, 302, 1181-1185.

Kubota, K., \& NiKi, H. (1971). Prefrontal cortical unit activity and delayed alternation performance in monkeys. Journal of Neurophysiology, 34, 337-347.

LEVY, R., \& GoldMAN-RAKIC, P. S. (2000). Segregation of working memory functions within the dorsolateral prefrontal cortex. Experimental Brain Research, 133, 23-32.

LiU, T., Slotnick, S. D., SEREnCes, J. T., \& Yantis, S. (2003). Cortical mechanisms of feature-based attentional control. Cerebral Cortex, 13, 1334-1343.

LucK, S. J., \& Vogel, E. K. (1997). The capacity of visual working memory for features and conjunctions. Nature, 390, 279-281.

Martin, A., Wiggs, C. L., Ungerleider, L. G., \& HaXbY, J. V. (1996). Neural correlates of category-specific knowledge. Nature, 379, 649652.

Maviel, T., Durkin, T. P., Menzaghi, F., \& Bontempi, B. (2004). Sites of neocortical reorganization critical for remote spatial memory. Science, 305, 96-99.

McCarthy, G., Puce, A., Constable, R. T., Krystal, J. H., Gore, J. C., \& Goldman-RaKic, P. [S.] (1996). Activation of human prefrontal cortex during spatial and nonspatial working memory tasks measured by functional MRI. Cerebral Cortex, 6, 600-611.

Mecklinger, A., Gruenewald, C., Besson, M., Magnié, M.-N., \& von Cramon, D. Y. (2002). Separable neuronal circuitries for manipulable and non-manipulable objects in working memory. Cerebral Cortex, 12, 1115-1123.

Mellet, E., Tzourio, N., Crivello, F., Joliot, M., Denis, M., \& MAZOYER, B. (1996). Functional anatomy of spatial mental imagery generated from verbal instructions. Journal of Neuroscience, 16, 65046512.

Miller, E. K., \& Cohen, J. D. (2001). An integrative theory of prefrontal cortex function. Annual Review of Neuroscience, 24, 167-202.

Miller, E. K., Erickson, C. A., \& Desimone, R. (1996). Neural mechanisms of visual working memory in prefrontal cortex of the macaque. Journal of Neuroscience, 16, 5154-5167.

MishKIN, M., \& MANNING, F. J. (1978). Non-spatial memory after selective prefrontal lesions in monkeys. Brain Research, 143, 313-323.

Mottaghy, F. M., Gangitano, M., Sparing, R., Krause, B. J., \& Pascual-Leone, A. (2002). Segregation of areas related to visual working memory in the prefrontal cortex revealed by rTMS. Cerebral Cortex, 12, 369-375.

Munk, M. H. J., Linden, D. E. J., Muckli, L., Lanfermann, H., ZANELla, F. E., Singer, W., \& Goebel, R. (2002). Distributed cortical systems in visual short-term memory revealed by event-related functional magnetic resonance imaging. Cerebral Cortex, 12, 866-876.

Murray, E. A., Bussey, T. J., \& Wise, S. P. (2000). Role of prefrontal cortex in a network for arbitrary visuomotor mapping. Experimental Brain Research, 133, 114-129.

Nystrom, L. E., B RaVER, T. S., SabB, F. W., Delgado, M. R., Noll, D. C., \& Cohen, J. D. (2000). Working memory for letters, shapes, and locations: fMRI evidence against stimulus-based regional organization in human prefrontal cortex. NeuroImage, 11, 424-446.

O'Craven, K. M., Downing, P. E., \& Kanwisher, N. (1999). fMRI evidence for objects as the units of attentional selection. Nature, $\mathbf{4 0 1}$, 584-587. 
Ohbayashi, M., Ohкi, K., \& Miyashita, Y. (2003). Conversion of working memory to motor sequence in the monkey premotor cortex. Science, 301, 233-236.

OLIVER, R. T., \& THOMPSON-Schill, S. L. (2003). Dorsal stream activation during retrieval of object size and shape. Cognitive, Affective, \& Behavioral Neuroscience, 3, 309-322.

OLSON, C. R., (2003). Brain representation of object-centered space in monkeys and humans. Annual Review of Neuroscience, 26, 331-354.

O'Reilly, R. C., Noelle, D. C., Braver, T. S., \& Cohen, J. D. (2002). Prefrontal cortex and dynamic categorization tasks: Representational organization and neuromodulatory control. Cerebral Cortex, 12, 246257.

Ó Scalaidhe, S. P., Wilson, F. A., \& Goldman-Rakic, P. S. (1997). Areal segregation of face-processing neurons in prefrontal cortex. Science, 278, 1135-1138.

Ó Scalaid He, S. P., Wilson, F. A., \& Goldman-Rakic, P. S. (1999). Face-selective neurons during passive viewing and working memory performance of rhesus monkeys: Evidence for intrinsic specialization of neuronal coding. Cerebral Cortex, 9, 459-475.

Owen, A. M., Evans, A. C., \& Petrides, M. (1996). Evidence for a two-stage model of spatial working memory processing within the lateral frontal cortex: A positron emission tomography study. Cerebral Cortex, 6, 31-38.

Owen, A. M., Milner, B., Petrides, M., \& Evans, A. C. (1996). Memory for object features versus memory for object location: A positronemission tomography study of encoding and retrieval processes. Proceedings of the National Academy of Sciences, 93, 9212-9217.

Owen, A. M., Stern, C. E., Look, R. B., Tracey, I., Rosen, B. R., \& Petrides, M. (1998). Functional organization of spatial and nonspatial working memory processing within the human lateral frontal cortex. Proceedings of the National Academy of Sciences, 95, 77217726.

Paulesu, E., Frith, C. D., \& Frackowiak, R. S. (1993). The neural correlates of the verbal component of working memory. Nature, $\mathbf{3 6 2}$, 342-343.

Petit, L., Orssaud, C., Tzourio, N., Crivello, F., Berthoz, A., \& MAzoyer, B. (1996). Functional anatomy of a prelearned sequence of horizontal saccades in humans. Journal of Neuroscience, 16, 37143726.

Petrides, M. (1995a). Functional organization of the human frontal cortex for mnemonic processing: Evidence from neuroimaging studies. In J. Grafman, K. J. Holyoak, \& F. Boller (Eds.), Structure and function of the human prefrontal cortex (Annals of the New York Academy of Sciences, Vol. 769, pp. 85-96). New York: New York Academy of Sciences.

PETRIDES, M. (1995b). Impairments on nonspatial self-ordered and externally ordered working memory tasks after lesions of the middorsal part of the lateral frontal cortex in the monkey. Journal of Neuroscience, 15, 359-375.

Petrides, M., A Livisatos, B., \& Frey, S. (2002). Differential activation of the human orbital, mid-ventrolateral, and mid-dorsolateral prefrontal cortex during the processing of visual stimuli. Proceedings of the National Academy of Sciences, 99, 5649-5654.

PeTRIDES, M., \& PandYa, D. N. (2002). Comparative cytoarchitectonic analysis of the human and the macaque ventrolateral prefrontal cortex and corticocortical connection patterns in the monkey. European Journal of Neuroscience, 16, 291-310.

PoLlMANN, S., \& VON CRAMON, D. Y. (2000). Object working memory and visuospatial processing: Functional neuroanatomy analyzed by event-related fMRI. Experimental Brain Research, 133, 12-22.

Poremba, A., Saunders, R. C., Crane, A. M., CoOK, M., SoKoloff, L., $\&$ Mishrin, M. (2003). Functional mapping of the primate auditory system. Science, 299, 568-572.

Postle, B. R., \& D'EsPosito, M. (1999). "What"-then-"where" in visual working memory: An event-related fMRI study. Journal of Cognitive Neuroscience, 11, 585-597.

Postle, B. R., Stern, C. E., Rosen, B. R., \& Corkin, S. (2000). An fMRI investigation of cortical contributions to spatial and nonspatial visual working memory. NeuroImage, 11, 409-423.

Postle, B. R., Zarahn, E., \& D'Esposito, M. (2000). Using eventrelated $\mathrm{fMRI}$ to assess delay-period activity during performance of spatial and nonspatial working memory tasks. Brain Research Protocols, 5, 57-66.

PrabHaKARAN, V., Narayanan, K., Zhao, Z., \& Gabrieli, J. D. (2000). Integration of diverse information in working memory within the frontal lobe. Nature Neuroscience, 3, 85-90.

Quintana, J., YAJeYA, J., \& Fuster, J. M. (1988). Prefrontal representation of stimulus attributes during delay tasks: I. Unit activity in cross-temporal integration of sensory and sensory-motor information. Brain Research, 474, 211-221.

Rainer, G., AsaAd, W. F., \& Miller, E. K. (1998a). Memory fields of neurons in the primate prefrontal cortex. Proceedings of the National Academy of Sciences, 95, 15008-15013.

RAINER, G., ASAAD, W. F., \& Miller, E.K. (1998b). Selective representation of relevant information by neurons in the primate prefrontal cortex. Nature, 393, 577-579.

RajkowsKa, G., \& Goldman-Rakic, P. S. (1995). Cytoarchitectonic definition of prefrontal areas in the normal human cortex: II. Variability in locations of areas 9 and 46 and relationship to the Talairach coordinate system. Cerebral Cortex, 5, 323-337.

RÄMÄ, P., \& CourTney, S. M. (2005). Functional topography of working memory for face or voice identity. NeuroImage, 24, 224-234.

Rämä, P., Poremba, A., Yee, L., Malloy, M., Mishkin, M., \& CourTNEY, S. M. (2004). Dissociable functional cortical topographies for working memory maintenance of voice identity and location. Cerebral Cortex, 14, 768-780.

Rämä, P., Sala, J. B., Gillen, J. S., Pekar, J. J., \& Courtney, S. M. (2001). Dissociation of the neural systems for working memory maintenance of verbal and nonspatial visual information. Cognitive, Affective, \& Behavioral Neuroscience, 1, 161-171.

RAMNANI, N., \& OWEN, A. M. (2004). Anterior prefrontal cortex: Insights into function from anatomy and neuroimaging. Nature Reviews Neuroscience, 5, 184-194.

RAO, S. C., RAINER, G., \& Miller, E. K. (1997). Integration of what and where in the primate prefrontal cortex. Science, 276, 821-824.

RAuschecker, J. P., \& Tian, B. (2000). Mechanisms and streams for processing of "what" and "where" in auditory cortex. Proceedings of the National Academy of Sciences, 97, 11800-11806.

RobBINs, T. W. (2000). Chemical neuromodulation of frontal-executive functions in humans and other animals. Experimental Brain Research, 133, 130-138.

Robertson, L., Treisman, A., Friedman-Hill, S., \& Grabowecky, M. (1997). The interaction of spatial and object pathways: Evidence from Balint's syndrome. Journal of Cognitive Neuroscience, 9, 295-317.

Roe, K., Debruin, D., Roth, J. K., \& Courtney, S. M. (2003). Dorsal/ ventral dissociation for nonspatial visual versus verbal working memory (CD-ROM, Program No. 343.3, Abstracts viewer/itinerary planner). Washington, DC: Society for Neuroscience.

Romanski, L. M., Tian, B., Fritz, J., Mishkin, M., Goldman-Rakic, P. S., \& RAuscheckeR, J. P. (1999). Dual streams of auditory afferents target multiple domains in the primate prefrontal cortex. Nature Neuroscience, 12, 1131-1136.

Roth, J. K., SErences, J., \& Courtney, S. M. (2004). Role of parietal and frontal cortices in updating and refreshing the contents of working memory. NeuroImage, 22, S69.

Rowe, J. B., Toni, I., Josephs, O., Frackowiak, R. S., \& Passingham, R. E. (2000). The prefrontal cortex: Response selection or maintenance within working memory? Science, 288, 1656-1660.

Rushworth, M. F., Nixon, P. D., EACOTT, M. J., \& PASSINGHam, R. E. (1997). Ventral prefrontal cortex is not essential for working memory. Journal of Neuroscience, 17, 4829-4838.

SaKaI, K., \& Passingham, R. E. (2003). Prefrontal interactions reflect future task operations. Nature Neuroscience, 6, 75-81.

SAKaI, K., Rowe, J. B., \& PAssingham, R. E. (2002). Active maintenance in prefrontal area 46 creates distractor-resistant memory. $\mathrm{Na}$ ture Neuroscience, 5, 479-484.

SALA, J. B. (2003). Active maintenance and the binding of information during working memory. Unpublished doctoral dissertation, Johns Hopkins University, Baltimore.

SAlA, J. B., RÄMÄ, P., \& Courtney, S. M. (2003). Functional topography of a distributed neural system for spatial and nonspatial information maintenance in working memory. Neuropsychologia, 41, 341-356. 
Sayala, S., Sala, J. B., \& Courtney, S. M. (2004). Domain-specific and domain-general changes in $\mathrm{fMRI}$ activation during repeated performance of working memory tasks. NeuroImage, 22, S50.

Schmitz, T. W., KaWahara-Baccus, T. N., \& Johnson, S. C. (2004). Metacognitive evaluation, self-relevance, and the right prefrontal cortex. NeuroImage, 22, 941-947.

Schoenfeld, M. A., Tempelmann, C., Martinez, A., Hopf, J. M., Sattler, C., Heinze, H. J., \& Hillyard, S. A. (2003). Dynamics of feature binding during object-selective attention. Proceedings of the National Academy of Sciences, 100, 11806-11811.

Serences, J. T., Schwarzbach, J., Courtney, S. M., Golay, X., \& YANTIS, S. (2004). Control of object-based attention in human cortex. Cerebral Cortex, 14, 1346-1357.

Serences, J. T., Shomstein, S., Leber, A. B., Golay, X., Egeth, H. E., \& YANTIS, S. (in press). Coordination of voluntary and stimulusdriven attentional control in human cortex. Psychological Science.

Smith, E. E., \& Jonides, J. (1999). Storage and executive processes in the frontal lobes. Science, 283, 1657-1661.

SMith, E. E., Jonides, J., \& KoEPPE, R. A. (1996). Dissociating verbal and spatial working memory using PET. Cerebral Cortex, 6, 11-20.

Smith, E. E., Jonides, J., Koepre, R. A., Awh, E., Schumacher, E. H., \& Minoshima, S. (1995). Spatial versus object working memory: PET investigations. Journal of Cognitive Neuroscience, 7, 337-356.

STARK, C. E., \& SQuire, L. R. (2001). When zero is not zero: The problem of ambiguous baseline conditions in fMRI. Proceedings of the National Academy of Sciences, 98, 12760-12766.

Stern, C. E., Owen, A. M., Tracey, I., LoOK, R. B., Rosen, B. R., \& Petrides, M. (2000). Activity in ventrolateral and mid-dorsolateral prefrontal cortex during nonspatial visual working memory processing: Evidence from functional magnetic resonance imaging. NeuroImage, 11, 392-399.

StOET, G., \& SNYDER, L. H. (2004). Single neurons in posterior parietal cortex of monkeys encode cognitive set. Neuron, 42, 1003-1012.

Ungerleider, L. G., \& HAXBY, J. V. (1994). "What" and"where" in the human brain. Current Opinion in Neurobiology, 4, 157-165.

UNGERLEIDER, L. G., \& MishKIN, M. (1982). Two cortical visual systems. In D. J. Ingle, M. A. Goodale, \& R. J. W. Mansfield (Eds.), Analysis of visual behavior (pp. 549-586). Cambridge, MA: MIT Press.
Vandenberghe, R., Gitelman, D. R., Parrish, T. B., \& Mesulam, M. M. (2001). Functional specificity of superior parietal mediation of spatial shifting. NeuroImage, 14, 661-673.

Wallis, J. D., Anderson, K. C., \& Miller, E. K. (2001). Single neurons in the prefrontal cortex encode abstract rules. Nature, 411, 953956.

Wheeler, M. E., \& Treisman, A. M. (2002). Binding in short-term visual memory. Journal of Experimental Psychology: General, 131, 48-64.

White, I. M., \& Wise, S. P. (1999). Rule-dependent neuronal activity in the prefrontal cortex. Experimental Brain Research, 126, 315-335.

Williams, G. V., \& Goldman-RaKic, P. S. (1995). Modulation of memory fields by dopamine D1 receptors in prefrontal cortex. $\mathrm{Na}$ ture, 376, 572-575.

Williams, G. V., RaO, S. G., \& Goldman-RaKic, P. S. (2002). The physiological role of 5-HT2A receptors in working memory. Journal of Neuroscience, 22, 2843-2854.

Wilson, F. A., Ó SCALAidhe, S. P., \& Goldman-RaKic, P. S. (1993). Dissociation of object and spatial processing domains in primate prefrontal cortex. Science, 260, 1955-1958.

WOJCIULIK, E., \& KANWISHER, N. (1999). The generality of parietal involvement in visual attention. Neuron, 23, 747-764.

Wood, J. N., \& Grafman, J. (2003). Human prefrontal cortex: processing and representational perspectives. Nature Reviews Neuroscience, 4, 139-147.

Yajeya, J., Quintana, J., \& Fuster, J. M. (1988). Prefrontal representation of stimulus attributes during delay tasks: II. The role of behavioral significance. Brain Research, 474, 222-230.

Yantis, S., Schwarzbach, J., Serences, J. T., Carlson, R. L., Steinmetz, M. A., Pekar, J. J., \& Courtney, S. M. (2002). Transient neural activity in human parietal cortex during spatial attention shifts. Nature Neuroscience, 5, 995-1002.

YeE, T. S. L., Sala, J. B., \& Courtney, S. M. (2003). Differential dorsal and ventral activation in shape versus color working memory. (CD-ROM, Program No. 287.16, Abstracts viewer/itinerary planner). Washington, DC: Society for Neuroscience.

Zarahn, E., Aguirre, G. K., \& D'Esposito, M. (1999). Temporal isolation of the neural correlates of spatial mnemonic processing with f MRI. Cognitive Brain Research, 7, 255-268. 